\title{
DIREITOS DE APRENDIZAGEM DE LÍNGUA PORTUGUESA: APROFUNDAMENTO NECESSÁRIO
}

\author{
Andréa Ramos de Oliveira ${ }^{1}$, Ana Luzia Videira Parisotto ${ }^{2}$ \\ ${ }^{1}$ Doutoranda pela Universidade Estadual Paulista (UNESP), campus de Presidente Prudente. Supervisora de Ensino. E-mail: \\ andrearamos_os@hotmail.com \\ ${ }^{2}$ Doutora em Letras pela Universidade Estadual Paulista (UNESP), campus de Assis. Docente do Departamento de Educação e do Programa de Pós- \\ Graduação em Educação da Universidade Estadual Paulista (UNESP), campus de Presidente Prudente.
}

\section{RESUMO}

O presente texto, recorte de dissertação de mestrado em Educação, tem como foco os direitos de aprendizagem apresentados no Pacto Nacional pela Alfabetização na Idade Certa (PNAIC) - Língua Portuguesa. O objetivo deste estudo foi apresentar a percepção dos professores participantes da pesquisa sobre os direitos e o tratamento dado durante o Pacto. A metodologia constou de um estudo de caso e para a geração de dados, neste artigo, foi utilizada a entrevista coletiva. Os resultados evidenciam que as professoras elogiaram o material de formação, o acervo literário e a socialização de práticas, criticaram a carga horária e a organização dos encontros, a mediação dos formadores e ressaltaram que os direitos de aprendizagem se mostraram uma novidade, mas que não houve aprofundamento do estudo sobre eles. Concluímos que os direitos de aprendizagem foram apresentados de forma desarticulada à formação proposta durante o PNAIC.

Palavras-chave: PNAIC, formação de professores, direitos de aprendizagem, ensino de língua materna, alfabetização.

\section{PORTUGUESE LANGUAGE LEARNING RIGHTS: NECESSARY APPROPRIATION}

\begin{abstract}
The present text, cutting out of dissertation of master's degree in Education, takes as a focus the of learning rights of in the Continuing Education Program 2013 - Portuguese Language. The objective of this study was participants of the inquiry presented the perception of the teachers on the rights and the treatment given during the Pact. The methodology consisted of a case study and for the generation of data, in this article, the press conference was used. The results show up that the teachers praised the material of formation, the literary heap and the socialization of practices, they criticized the workload and the organization of the meetings, the mediation of the formers and emphasized that the learning rights showed a novelty, but that there was no deepening of the study on them. We end that the learning rights were presented in the form dislocated to the formation proposed during the PNAIC.
\end{abstract}

Keywords: PNAIC, teacher training, learning rights, native language teaching, literacy.

\section{INTRODUÇÃO}

A discussão sobre a qualidade da educação pública brasileira não é recente; vencido o desafio do acesso, vive-se o momento de garantir o oferecimento de um "serviço público" qualitativo, o que tem guiado políticas e ações sociais. Nesse contexto de "busca da qualidade", as questões relativas à alfabetização têm se agigantado, na mesma proporção dos índices nacionais que a evidenciam, o que motivou o governo federal a implantar o Pacto Nacional pela Alfabetização na Idade Certa
(PNAIC), um programa de formação continuada de professores alfabetizadores, em âmbito nacional, firmado entre o Ministério da Educação (MEC), secretarias de educação estaduais, municipais e distrital e universidades públicas brasileiras, cuja primeira edição se deu em 2013, com foco em Língua Portuguesa para atender a meta de alfabetizar todas as crianças até, no máximo, os 8 anos de idade, ao final do 3 을 ano do Ensino Fundamental.

A abrangência do Pacto denota a sua importância, sendo caracterizado como o maior 
programa de formação de professores já desenvolvido MEC (BRASIL, 2015). O processo de formação continuada foi, em 2013, coordenado por 38 IES, das quais 31 federais e 7 estaduais, e, segundo Documento Orientador do Pacto 2014 (BRASIL, 2014, p. 2), envolveu “[...] 53 coordenadores estaduais, 5424 coordenadores municipais, 78 coordenadores no âmbito das IES, 170 supervisores (IES), 645 formadores (IES), 15.950 orientadores de estudos e 317.462 professores alfabetizadores das redes estaduais e municipais de ensino". Quanto aos municípios participantes, no ano da implantação, o PNAIC contou, dentre os 5.570 municípios brasileiros, com um total de 5.420 (97,31\%) municípios, distribuídos por 27 estados e o Distrito Federal, o que revela que os municípios acreditaram no Pacto como alternativa para alfabetização de todas as crianças até os 8 anos de idade e investiram na parceria com o governo federal.

Para atingir o objetivo a que se propôs, o PNAIC apresentou aos professores cursistas os direitos de aprendizagem nas diferentes áreas de conhecimento. No que concerne ao trabalho de Língua Portuguesa, foram apresentados os seguintes direitos gerais de aprendizagem, que se encontram organizados no Quadro 1:

Quadro 1. Direitos Gerais de Aprendizagem em Língua Portuguesa

Compreender e produzir textos orais e escritos de diferentes gêneros, veiculados em suportes textuais diversos, e para atender a diferentes propósitos comunicativos, considerando as condições em que os discursos são criados e recebidos.

Apreciar e compreender textos do universo literário (contos, fábulas, crônicas, poemas, dentre outros), levando-se em conta os fenômenos de fruição estética, de imaginação e de lirismo, assim como os múltiplos sentidos que o leitor pode produzir durante a leitura.

Apreciar e usar em situações significativas os gêneros literários do patrimônio cultural da infância, como parlendas, cantigas, trava línguas.

Compreender e produzir textos destinados à organização e socialização do saber escolar/científico (textos didáticos, notas de enciclopédia, verbetes, resumos, resenhas, dentre outros) e à organização do cotidiano escolar e não escolar (agendas, cronogramas, calendários, cadernos de notas...).

Participar de situações de leitura/escuta e produção oral e escrita de textos destinados à reflexão e discussão acerca de temas sociais relevantes (notícias, reportagens, artigos de opinião, cartas de leitores, debates, documentários...).

Produzir e compreender textos orais e escritos com finalidades voltadas para a reflexão sobre valores e comportamentos sociais, planejando e participando de situações de combate aos preconceitos e atitudes discriminatórias (preconceito racial, de gênero, preconceito a grupos sexuais, preconceito linguístico, dentre outros).

Fonte: Caderno de formação do Pacto pela Alfabetização (BRASIL, 2012, unidade 1, ano 3, p. 30). Disponível em http://pacto.mec.gov.br/images/pdf/Formacao/Ano_3_Unidade_1_MIOLO.pdf. Acesso em: 06 ago. 2017.

A leitura mais criteriosa desses direitos revela o diálogo estabelecido com os Parâmetros Curriculares Nacionais de Língua Portuguesa PCNs (1997) e reforça a importância e o valor dos usos sociais da linguagem. A grande dificuldade, no entanto, parece ser a da própria escola brasileira que perpetua "[...] práticas de ensino que tratam a língua como algo sem vida e os textos como conjunto de regras a serem aprendidas" (BRASIL, 1997, p. 25).

O objetivo deste estudo centra-se na apresentação da percepção dos professores participantes da pesquisa sobre os direitos e o tratamento dado durante o Pacto. As considerações ora apresentadas, recortes de estudo mais amplo, integram pesquisa de mestrado que investigou as contribuições oportunizadas, na área de Língua Portuguesa, pelo Pacto Nacional pela Alfabetização na Idade Certa (PNAIC) - à prática de professores do terceiro ano do Ensino Fundamental em duas escolas selecionadas da rede municipal de ensino de Birigui/SP, segundo o entendimento desses professores alfabetizadores e de gestores escolares.

\section{METODOLOGIA}

Esta seção apresenta a metodologia em que se enquadra a pesquisa empírica - estudo de caso de natureza qualitativa e interpretativa -, submetida ao Comitê de Ética em Pesquisa e aprovada para desenvolvimento - CAAE: 53028916.6.0000.5402, comprovante no 
007404/2016, com notificação de comunicação de término do projeto em 15/05/2017.

Optou-se por se realizar um estudo de caso pela possibilidade de analisar o fenômeno estudado considerando-se as particularidades dos sujeitos, das escolas e do município selecionados de forma que permitissem a compreensão da questão-problema: "qual a relação que se pode estabelecer entre a formação continuada de professores efetivada a partir de programas governamentais e a ação docente propriamente dita?"

Segundo Fonseca (2002, p. 33),

Um estudo de caso pode ser caracterizado como um estudo de uma entidade bem definida como um programa, uma instituição, um sistema educativo, uma pessoa, ou uma unidade social. Visa conhecer em profundidade o como e o porquê de uma determinada situação que se supõe ser única em muitos aspectos, procurando descobrir o que há nela de mais essencial e característico. 0 pesquisador não pretende intervir sobre 0 objeto a ser estudado, mas revelá-lo tal como ele o percebe. $O$ estudo de caso pode decorrer de acordo com uma perspectiva interpretativa, que procura compreender como é o mundo do ponto de vista dos participantes, ou uma perspectiva pragmática, que visa simplesmente apresentar uma perspectiva global, tanto quanto possível completa e coerente, do objeto de estudo do ponto de vista do investigador.

Para a geração de dados, utilizou-se a entrevista coletiva, cuja opção se deu para que as professoras envolvidas não se sentissem acuadas ou pressionadas, mas para que percebessem a importância de serem ouvidas e respeitadas, independentemente de suas posições assumidas. Freitas, Souza e Kramer (2007, p. 65) explicam que "Nas entrevistas coletivas, a situação dialógica é enriquecida, as análises são mais profundas e substanciais e, acima de tudo, a perplexidade é expressa".

A entrevista coletiva aconteceu em uma das escolas pesquisadas, no dia 14 de fevereiro de 2017, no período que antecede o HTPC, com tempo breve, em torno de 30 minutos de duração, e contou com a participação de cinco docentes que foram cursistas do PNAIC/2013, a quem foram feitas três perguntas: 1 . Como vocês avaliam o PNAIC/2013 e por quê?; 2. O que consideram que foi mais positivo no programa e nos encontros formativos?; 3. Quais aspectos mereceriam ser repensados e por quê?

Os dados foram tabulados e analisados segundo a análise de conteúdo proposta por Bardin (2011), cujos elementos tornam-se importante contributo, segundo Berelson (apud BARDIN, 2011, p. 42), por ser entendida como “[...] uma técnica de investigação que através de uma descrição objetiva, sistemática e quantitativa do conteúdo manifesto das comunicações tem por finalidade a interpretação destas mesmas comunicações" [grifo do autor].

\section{RESULTADOS}

Solicitou-se que as professoras evidenciassem como avaliaram, de fato, o PNAIC/2013 (se foi bom ou ruim, se contribuiu ou não para o trabalho) e que se posicionassem se toda a mobilização do governo federal contribuiu para que houvesse mudanças no seu fazer pedagógico, a fim de que colaborassem para as conclusões da pesquisa desenvolvida.

A primeira professora a se manifestar disse que muitos dos conceitos apresentados já eram trabalhados por elas, sendo assim, no começo não havia muita novidade. A rede municipal vinha desenvolvendo ações formativas com foco no trabalho com gêneros textuais e já discutia a organização do trabalho por sequências didáticas, ainda que se reconheça que muito careça ser desenvolvido nesse aspecto. $O$ que a fala da professora revela é que não houve, no campo dos conceitos, algo avaliado por elas como "novo" e que chamasse a atenção para o inusitado.

As entrevistadas qualificaram como algo "ótimo", "perfeito" o acervo de livros enviado para as escolas. Pondera-se que os acervos literários das escolas nem sempre apresentam a variedade e a quantidade de obras tidas como necessárias para o desenvolvimento de boas 
ações com a leitura no espaço escolar. A precariedade de algumas unidades no que concerne a essa questão fez com que os professores "festejassem" as "caixas do PNAIC", porque reconhecem a importância de livros de qualidade literária na formação do aluno leitor. Ressalta-se que o material do Pacto trouxe algumas sugestões de trabalho com obras complementares e jogos, como é constatado na seção Compartilhando, do Caderno "O último ano do ciclo de alfabetização: consolidando os conhecimentos", Ano 03, Unidade 03 (BRASIL, 2012).

A docente que primeiro se posicionou considerou que houve falta de acompanhamento ou de "respaldo" por parte dos orientadores de estudo, que não conseguiam responder às dúvidas apresentadas ou levadas para discussão pelas cursistas. Analisando-se as pautas sugeridas em cada caderno para os encontros em grupo, percebe-se que nem sempre os encaminhamentos propostos eram os que aconteciam nos encontros de formação, que reproduziam mais o material disponibilizado pela IES do que retratavam uma apropriação do município.

A segunda professora apontou como uma "inovação" a apresentação dos direitos de aprendizagem, o que o grupo reforçou como concordância, mas houve a ressalva de que isso não se mostra um conhecimento consolidado, ao que as entrevistadas acrescentam ter ainda muitas dúvidas, não ter claro, carecer de aprofundamento.

Quando foram apresentados, os docentes tiveram contato com todos os quadros dos direitos de aprendizagem, nas mais diversas áreas do currículo, uma espécie de apreciação do texto que continham. Pode ter dado a impressão de que era "muito" a ser feito, sem que tenha acompanhado essa apresentação a reflexão de que os quadros não passam de uma sistematização do tanto que já se faz. Pensar a organização do trabalho a partir dos direitos de aprendizagem força o professor a determinar objetivos para a sua ação e formaliza o compromisso da aprendizagem que deve ser garantida. No entanto, dadas as condições da apresentação, o entendimento docente foi de que, além de habilidades do plano de ensino e das descritas nas matrizes de referência de avaliações externas, somam-se os direitos de aprendizagem. $\mathrm{O}$ professor se sente pressionado por exigências externas e determinações legais que nem sempre consideram o que acontece na escola, em salas de aulas com 25 a 30 alunos em turmas de alfabetização, nem sempre com recursos disponíveis, nem sempre em espaços físicos em boas condições.

Sobre a carga horária e a organização dos encontros formativos, as entrevistadas salientam que a distribuição do curso aos sábados foi "massacrante", principalmente para os que aconteciam o dia todo (8h) e que os encontros não foram aproveitados para o aprofundamento do que elas julgavam ser necessário (os direitos de aprendizagem). Para uma das docentes, os direitos de aprendizagem foram "citados", mas não "trabalhados". Para as entrevistadas, a concentração da formação aos sábados ficava muito cansativa, principalmente para aquelas que acumulam cargos, uma situação recorrente entre a classe docente no contexto atual.

Questionadas sobre a contribuição da socialização de práticas, uma das entrevistadas disse que foi o que de melhor aconteceu, porque permitiu conhecer $o$ trabalho de outros professores. Ressaltou que, algumas vezes, a formadora não dava muita opinião, direcionando o que precisava ser melhorado, mas a professora enfatiza que o grupo, as professoras cursistas, fazia essa avaliação e opinava sobre os aspectos que eram considerados bons ou que careciam de reflexão para "dar certo". Dubar (1997, p. 13) afirma que "[...] a identidade [do professor como profissional] é um produto de sucessivas socializações".

As professoras concluem que os encontros falharam na mediação do formador; em alguns momentos dos encontros formativos, o que se percebia era a reprodução da pauta discutida nas formações recebidas pelos Orientadores de Estudo, e "cumprir a pauta" era considerado de maior importância do que as discussões fomentadas pelos participantes. Nem sempre as ânsias, as angústias, as dúvidas da sala de aula tinham espaço no PNAIC e permaneciam com os docentes. Ponderam que houve pontos que deveriam ter sido mais trabalhados, que o material foi de boa qualidade e que, em alguns momentos, serve de "cartilha" no dia a dia, mesmo que se reconheça que, nos encontros, não tenham sido explorados em sua profundidade e totalidade.

\section{DISCUSSÃO}

Para as professoras, evidencia-se que houve uma carência não suprida nos encontros 
do PNAIC. Propostas de formação aligeiradas não satisfazem os que querem construir e construirse. Essa constatação ajuda a pensar programas de formação continuada para que não desconsiderem os saberes (e as dúvidas) dos professores, porque é a partir disso que novos saberes podem ser construídos e é nessa construção que o aprendizado das crianças pode ser edificado e confirmado.

A entrevista coletiva revelou descontentamento docente com relação ao tratamento dos direitos de aprendizagem, à falta de intervenção por parte dos orientadores de estudo aos trabalhos apresentados e com a organização dos encontros aos sábados, principalmente àqueles que tinham oito horas de duração. As ânsias que as professoras traziam não encontravam espaço para serem discutidas e, em alguns momentos, o que tiveram foram "aulas de PNAIC".

Uma questão que merece destaque no tocante aos direitos de aprendizagem é a apresentação do quadro que trata do eixo Produção de textos escritos. Os direitos de aprendizagem indicados nesse quadro mostram que as crianças devem: planejar a escrita de textos; produzir textos de diferentes gêneros; gerar e organizar o conteúdo textual; revisar os textos durante o processo da escrita; revisar os textos após diferentes versões, reescrevendo-os (BRASIL, 2012, p. 34). Para Magalhães e Vargas (2015, p. 108-109),

Ao analisar o quadro, se obtém uma visão mais clara do percurso de aprendizagem da produção textual e da necessidade da promoção de atividades nas quais as crianças compreendam que escrever um texto implica na elaboração de um texto provisório que será revisado e reescrito e, posteriormente, editorado.

As exigências tocam essencialmente no que foi constatado ao longo do trabalho de investigação como dificuldade dos professores, daí, também, a insegurança gerada em relação aos direitos de aprendizagem. Alunos de uma escola que segmentou o ensino da língua portuguesa, os atuais professores nem sempre conseguem planejar propostas que articulem leitura, escrita, reflexão sobre a língua em práticas sociais de uso da língua. Os direitos de aprendizagem, pensados na perspectiva do alfabetizar letrando, se mostram complexos justamente por proporem um "fazer junto" do que "se aprendeu separado".

\section{CONCLUSÃO}

Com objetivo ousado - alfabetizar todas as crianças até o final do terceiro ano do Ensino Fundamental - e alto investimento financeiro em torno de $\mathrm{R} \$ 1,5$ bilhão somente para o ano de 2013 -, o PNAIC reforçou o discurso da alfabetização como prioridade nacional, mas ignorou que, num país cujos níveis de alfabetização se mostram tão destoantes, é impossível que o quadro de analfabetismo se reverta num curto período de tempo.

Com temática complexa e carga horária reduzida, o Pacto quis muito num curto período. Dessa forma, orientadores de estudo e professores cursistas não dialogaram o necessário e não aprofundaram os estudos sobre os direitos de aprendizagem. O "novo", que poderia representar o contributo necessário a uma discussão que já vem de longa data, desde a implantação dos PCNs, reduziu-se à apresentação e não se relacionou, conforme a opinião e necessidade das docentes pesquisadas, às práticas apresentadas durante os encontros formativos.

A questão problema posta - qual a relação que se pode estabelecer entre a formação continuada de professores efetivada a partir de programas governamentais e a ação docente propriamente dita? - revela uma correspondência mínima entre formação e mudança docente. A mudança não vem de fora, parte de necessidades de grupos e deve, por eles, ser sentida.

As concepções teóricas, embasadas na perspectiva dialógica da linguagem, no trabalho com gêneros e na elaboração de sequências didáticas, que fundamentaram o trabalho com a Língua Portuguesa no programa de formação continuada analisado, nem sempre foram incorporadas às práticas dos docentes sujeitos desta pesquisa, que muitas vezes continuaram fazendo o que já sabiam fazer sem agregar o "novo" que o programa trazia.

Retomadas as questões apresentadas na entrevista coletiva, as participantes qualificam o PNAIC como bom; dentre os elogios que tecem ao programa, as docentes pesquisadas 
apontaram como elemento de destaque a distribuição de material impresso para formação e de acervo literário para utilização na sala de aula. É importante ressaltar que o investimento em material que contribua para a formação do aluno leitor é de extrema necessidade nas escolas brasileiras e o Pacto trouxe essa preocupação e essa contribuição. Quanto aos encontros formativos, destacam como positiva a socialização de práticas. No tocante aos aspectos que merecem ser repensados, incluem 0 acompanhamento/medição das orientadoras de estudo, a abordagem dos direitos de aprendizagem e a organização dos encontros em dias diferentes do sábado. No tocante aos direitos de aprendizagem, como ponto de inovação, seu aprofundamento contribuiria para um melhor planejamento e desenvolvimento do trabalho com Língua Portuguesa.

\section{REFERÊNCIAS}

BARDIN, Laurence. Análise de conteúdo. São Paulo: Edições 70, 2011.

BRASIL. Secretara de Educação Fundamental. Parâmetros Curriculares Nacionais: primeiro e segundo ciclos do ensino fundamental: língua portuguesa. Brasília: SEF/MEC, 1997.

BRASIL. Secretaria de Educação Básica. Diretoria de Apoio à Gestão Educacional. Pacto nacional pela alfabetização na idade certa: currículo inclusivo: o direito de ser alfabetizado: ano 3: unidade 1. Ministério da Educação, Secretaria de Educação Básica, Diretoria de Apoio à Gestão Educacional. Brasília: MEC, SEB, 2012.

BRASIL. Secretaria de Educação Básica. Diretoria de Apoio à Gestão Educacional. Pacto nacional pela alfabetização na idade certa: o último ano do ciclo de alfabetização: consolidando os conhecimentos: ano 3: unidade 3. Ministério da Educação, Secretaria de Educação Básica, Diretoria de Apoio à Gestão Educacional. Brasília: MEC, SEB, 2012.

BRASIL. Pacto nacional pela alfabetização na idade certa. Documento orientador das ações de Formação em 2014. DAGE/SEB/MEC, janeiro, $2014 . \quad$ Disponível em: http://pacto.mec.gov.br/images/pdf/Formacao/d ocumento orientador 2014 versao site.pdf.

Acesso em: 02 ago. 2016.
BRASIL. Secretaria de Educação Básica. Diretoria de Apoio à Gestão Educacional. Pacto Nacional pela Alfabetização na Idade Certa. Interdisciplinaridade no ciclo de alfabetização. Caderno de Apresentação. Ministério da Educação, Secretaria de Educação Básica, Diretoria de Apoio à Gestão Educacional. Brasília: MEC, SEB, 2015.

DUBAR, Claude. A socialização: construção das identidades sociais e profissionais. Porto, Portugal: Porto Editora, 1997.

FONSECA, João José Saraiva da. Metodologia da pesquisa científica. Apostila do curso de especialização em comunidades virtuais de aprendizagem - informática educativa. Ceará: Universidade Estadual do Ceará, 2002.

FREITAS, Maria Teresa; SOUSA, Solange Jobim ; KRAMER, Sonia. Ciências humanas e pesquisa: leitura de Mikhail Bakhtin. 2. ed. São Paulo: Cortez, 2007.

MAGALHÃES, Luciane Manera; VARGAS, Suzana Lima. Produzindo textos escritos na alfabetização inicial. Educação em Foco, Juiz de Fora, v. 1, n. 1, p. 99-118, fev. 2015.

Recebido para publicação em: 08/08/2017

Revisado em: 01/09/2018

Aceito em: 04/09/2018 